\section{Enalapril therapy in Type 1 (insulin-dependent) diabetic children}

Dear Sir,

While accepting the suggestion from Drummond et al. [1] that an increase in glomerular filtration rate (GFR) is secondary to a rise in renal plasma flow, I am unsure that any other conclusions can be drawn from this study especially with reference to intervention for the prevention of long-term diabetic nephropathy. My concern centres around the selection of the subjects. These so-called hyper-filtering patients comprised 8 out of 18 subjects who had GFR within the group's own normal range. Drummond quoted a range up to $152 \mathrm{ml} \cdot \mathrm{min}^{-1} \cdot 1.73 \mathrm{~m}^{2-1}$ and yet arbitrarily chose a filtration rate over $145 \mathrm{ml}$ per min per $1.73 \mathrm{~m}^{2}$. (Incidentally, Subject three appears to have an initial GFR way below this value of 115 ; why was this patient included?)

The authors also point out that various hormonal and metabolic disturbances can account for a rise in GFR. They also point out that the mean blood glucose concentration for their subjects was elevated above a level liable to give glycosuria of a significant degree. Finally, the 8 subjects out of the 18 with the GFR above their normal range appeared to have a significantly higher duration of diabetes.

It is possible, therefore, that these patients were a combination of subjects whose GFR fell normally at the upper ranges, had marked metabolic instability at the time of the measurement and significant tissue damage secondary to glycosylation over a long time period. It is therefore quite probable that a short-term course of an angiotensin converting enzyme inhibitor would be unlikely to produce any response in these physiological measurements. It was interesting to note that there was a significant reduction in blood pressure during this short-term study. The physiological response to this change remains to be tested in the young early-onset Type 1 diabetic child.

Yours sincerely,

A. Greene

\section{Reference}

1. Drummond K, Levy-Marchal C, Laborde K, Kindermans C, Wright C, Dechaux M, Czernichow P (1989) Enalapril does not alter renal function in normotensive, normoalbuminuric, hyperfiltering Type 1 (insulin-dependent) diabetic children, Diabetologia $32: 255-260$

Dr. S. A. Greene

The University Dundee

Department of Child Health

Ninewells Hospital and Medical School

Dundee DD19SY

Scotland

UK 